\title{
Roser SAlicrú i Lluch (ED.), TRIPULACIONS I VAIXELLS A LA MEDITERRÁNIA MEDIEVAL. FONTS I PERSPECTIVES COMPARADES DES DE LA CORONA D’ARaGó, Publicacions de l'Abadia de MontSERRAT, BARCELONA, 2019, 423 PÁGS. ISBN: 978-84-9191-073-2.
}

CARolina Obradors-Suazo

En septiembre de 2014, se celebró en el Museo Marítimo de Barcelona un seminario internacional sobre fuentes documentales relacionadas con el mundo marítimo del Mediterráneo bajomedieval. En el marco del proyecto de investigación 'Tripulacions, armaments, construcció naval i navegació a la Mediterrània medieval,' pilotado por la Dra. Roser Salicrú i Lluch desde la Institució Milà i Fontanals del CSIC de Barcelona, el encuentro sentó las bases para un estudio renovado de la vida en el mar durante la Baja Edad Media, ofreciendo para ello una visión de conjunto sobre los fondos, fuentes y tipologías documentales que sobre estos temas se conservan en los archivos de la antigua Corona de Aragón. El volumen que reseñamos recupera ese empeño, compilando gran parte de las contribuciones de ese encuentro e incorporando algunas nuevas. Tripulacions $i$ vaixells se abre con una presentación clara y concisa de la editora en la que se identifica como objetivo clave del libro presentar las fuentes disponibles sobre el mundo marítimo en el marco histórico de la Corona de Aragón desde una perspectiva amplia y comparada. El volumen nace, en efecto, con la intención de poder contrastar formas de vida, de poder y de negociación en el mundo marítimo de la Corona de Aragón, pero insiste también en el potencial de la Corona y de las fuentes conservadas en sus archivos para erigirse en un observatorio privilegiado desde el que poder reflexionar sobre otras realidades marítimas mediterráneas e ibéricas. A esta presentación le siguen, por orden alfabético de los autores, diecisiete contribuciones que presentan con sus trabajos la variabilidad de las fuentes existentes y muestran cómo cada una de ellas permite dibujar el Mediterráneo bajomedieval como un espacio de vida, de intercambio, de ley, diplomacia y política. Se trata de fuentes normativas, institucionales, propiamente marítimas como el Manifest de Mar valenciano, los llibres d'acordament o los registros del ancoratge, diarios de bordo, correspondencia y fuentes notariales. Los autores parten de escenarios y contextos concretos (Barcelona, Valencia, Mallorca, 
Génova, Florencia, la guerra de los dos Pedros, las guerras de Italia, la flota imperial de 1500) y analizan las fuentes escogidas ahondando en alguno de los aspectos que estructuraban el mundo marítimo: las técnicas e infraestructuras de la construcción naval, el mercado naval, las tipologías de embarcaciones, las jerarquías en cubierta o la constitución y composición de las tripulaciones, entre otros. El volumen identifica así nuevas perspectivas de análisis que interesarán a los historiadores más especializados en la materia y se erige a la vez en una guía excelente para aquellos investigadores menos doctos que deseen hacer una incursión en el mundo marítimo medieval.

Mucho más que un catálogo de fuentes, este conjunto de contribuciones invita a reflexionar sobre las conexiones entre las diversas tipologías documentales que se mencionan, ofreciendo una visión global del escenario marítimo mediterráneo. Se hace así referencia a un Mediterráneo legislado tanto por las normas del libro de Consulado de Mar como por iniciativas locales como el Liber Gazarie genovés que intentaba adaptar la legislación propia a la de ese marco general (E.Basso, A. Musarra); siendo el Mediterráneo que se dibuja en estas páginas un espacio en el que la iniciativa privada se imponía sobre la pública (E.Basso) y las embarcaciones de tamaño medio sobre los buques de mayores dimensiones (D.Igual, M.Soberón). Fuentes notariales y municipales (D. Igual, J.L.Soler, M. Soberón, M. Hamelink) permiten reconstruir el ritmo cotidiano de este Mediterráneo volcado sobre el intercambio mercantil. Por otro lado, contribuciones como las de José Vicente Cabezuelo, Mario Orsi o Pinuccia Simbula retratan, sobre todo a través de registros de cancillería, la repetida excepción de la inversión marítima institucional por excelencia, la empresa bélica, liderada por monarcas como Pedro El Cerimonioso o Fernando El Católico que, con urgencia, movilizaban recursos por tierra y por mar para activar infraestructuras como las atarazanas de Barcelona y construir flotas con las que poder desafiar y defenderse de sus enemigos. Como bien indica Pinuccia Simbula, empresas de este calado dejan entrever el importante grado de imbricación que existía entre mundo marítimo y mundo urbano. La construcción de una flota empleaba a una variedad de artesanos urbanos, todos ellos liderados por un carpintero de ribera mayor (M. Hamelink), mientras que la tripulación se reclutaba entre los habitantes de la ciudad (R. Salicrú) y los oficiales reales y municipales que supervisaban la construcción se encargaban de gestionar la adquisición de materias primas, en ocasiones mucho más allá de las murallas urbanas.

Al complementarse con la vida en la ciudad, la vida en el mar no escapaba a la fiscalización. Al llegar a puerto, tanto las embarcaciones como las mercancías que transportaban podían ser objeto de tributación. En Valencia, el Manifest de Mar registraba la llegada de todo tipo de embarcaciones, anotando las mercancías que cargaban y las tributaciones que debían ser pagadas por ellas. Se mencionaba también cualquier excepción debida a los privilegios y franquezas de los mercaderes involucrados (D. Igual). En Barcelona, el dret d'ancoratge grababa las embarcaciones que atracaban en su playa, y lo hacía en función de su arqueo (M. Soberón). Cabe destacar que tanto David Igual como Mikel Soberón van más allá del elemento fiscal al analizar estas fuentes. Soberón utiliza los datos anotados por los colectores del ancoratge para trabajar sobre las tipologías de 
las embarcaciones que llegaban a Barcelona y su evolución a lo largo del siglo XV. Consciente de lo mucho que se ha trabajado sobre el Manifest, Igual opta por abrir una nueva vía de análisis, cruzando este registro de tipo fiscal con fuentes notariales para identificar así mejor a los hombres de mar que se mencionan en el Manifest. Con ello, obtiene información más precisa sobre la función de estos hombres como miembros de las tripulaciones y hace emerger la versatilidad de las ocupaciones de los hombres de mar, con marineros, calafates u escribanos de nave involucrados en el intercambio mercantil. Un ejemplo más, de otros tantos, de la fluidez de las ocupaciones, estatutos e identidades que componían la ciudad medieval.

Las contribuciones de Soberón e Igual son un ejemplo del esfuerzo que hace todo el volumen en su conjunto por releer fuentes, en muchas ocasiones conocidas, con la intención de reinterpretarlas y abrir nuevas perspectivas de análisis sobre el mundo marítimo bajomedieval. Como resultado general de este esfuerzo, cabe destacar, por ejemplo, el retrato detallado que ofrece el volumen de los diversos agentes que interactuaban en el mundo marítimo. En efecto, la diversidad de enfoques que proporciona el conjunto de contribuciones permite retratar la experiencia de la vida en el mar a partir de una multiplicidad de escenarios, momentos y procesos: la adquisición de materia prima para la construcción de embarcaciones, la actividad en las atarazanas, el enrolamiento de hombres de mar, los objetivos de misiones comerciales y bélicas, la gestión de la vida en alta mar, la llegada a puerto. Y con cada episodio, cada escena, se pone el foco sobre algunos de los perfiles que se gestaban en el mar: los monarcas y sus agentes como dirigentes de empresas bélicas y diplomáticas en cubierta, (J.M. Escribano, A. Reche), los diversos oficiales navales con funciones bien distintas por cumplir, ya fuesen conductores, patrones, capitanes o comisarios (R. González, J. L. Soler), los comerciantes como identidades maleables, que incluían a marineros y oficiales navales, los muy distintos perfiles que se juntaban para formar chusma y tripulación. El trabajo de Roser Salicrú es, quizás, el que mayor atención presta a la figura del enrolado. Tras contextualizar la producción de los registros de enrolamiento (llibres d'acordament) en el marco de la Corona, Salicrú se concentra en ejemplos barceloneses y lleva a cabo una minuciosa labor de identificación, con nombre y apellidos, de los miembros de algunas tripulaciones, sentando el tono de un trabajo micro analítico que logra evidenciar hasta qué punto los enrolados se fiaban entre sí en el momento de integrarse en una tripulación. Al embarcarse, los habitantes de Barcelona llevaban sus lazos consigo, facilitando que las redes sociales urbanas a las que pertenecían fueran también parte integrante de la estructura social de las tripulaciones.

La voluntad del volumen por abarcar la globalidad de los actores que hacían la vida en el mar se evidencia por el interés prestado a figuras de perfil técnico como eran los carpinteros de ribera y los calafates. A través de fuentes notariales (testamentos, inventarios, encantes), Marcel Hamelink traza las condiciones, jerarquías y ritmos de trabajo de estos artesanos especializados en las atarazanas de Barcelona y las playas de Sant Feliu de Guíxols. Tanto él como otros contribuyentes recuerdan que estos especialistas podían subirse también a cubierta con la misión de garantizar la seguridad del barco 
y poder reparar cualquier eventualidad durante las travesías. Se trataba pues, sin lugar a duda, de piezas fundamentales en el engranaje de la vida de una embarcación, tanto antes como después de hacerse a la mar. Por otra parte, son varias las contribuciones que subrayan la existencia y funciones del escribano de nave. Un notario a bordo, el escribano llevaba los libros de enrolamiento, los registros de aprovisionamiento y, en general, los ejercicios fiscales de las embarcaciones que supervisaba. Sus registros permiten seguir las rutas que seguían las embarcaciones, las mercancías que cargaban y delinear los orígenes de sus tripulantes (A. Musarra). Como tantos otros oficiales y marineros, aprovechaba su puesto para jugar también con la aventura mercantil (D. Igual). En Florencia, esta figura podía desdoblarse en un notario que registraba la carga y descarga de mercancías y un comisario, representante de los cónsules de mar, encargado de llevar un inventario del equipamiento y la lista de miembros de la tripulación (R. González). En todo caso, el escribano de nave se revaloriza en el libro, perfilándose como una figura crucial; en su tiempo por ser el garante de la organización y gestión de flotas enteras; hasta hoy por la memoria escrita que ha dejado de esa vida en el mar. José Miguel Escribano Páez hace del mundo marítimo un reflejo de los mecanismos sociales, institucionales y políticos que dibujaban la Monarquía Hispánica a principios del siglo XVI. Y lo hace con la clara voluntad metodológica de partir de los actores, centrándose en los agentes imperiales que lideraban y configuraban las flotas carolinas. Todo el volumen está imbuido por ese interés hacia el actor en el mundo naval del Mediterráneo bajomedieval. Así, el conjunto de las contribuciones logra releer fuentes, en su mayoría ya conocidas, para resaltar los roles y experiencias de estos perfiles diversos, sus actividades, relaciones, miedos, ambiciones y deserciones. De la mano de todos ellos se exploran muchos otros aspectos, desde la tecnología naval hasta la tipología de las embarcaciones, desde los procesos de formación de las tripulaciones hasta la profunda conexión entre tierra y mar. Así, Tripulacions $i$ vaixells completa con éxito la historiografía existente sobre el mundo marítimo bajomedieval, muy circunscrita hasta ahora, según algunos de los autores del volumen, a temas ligados con el comercio. Se trata de un volumen que, sin afán de exhaustividad, propone, abre, sugiere nuevas vías de estudio. En este sentido, es de esperar que el tono comparativo aportado por los casos italianos y el referido a la Monarquía Hispánica del 1500 pueda guiar hacia marcos comparativos aún más amplios, dirigiéndose, por ejemplo, hacia el mundo atlántico. Por ahora, el volumen cumple con creces su cometido, energizando con rigor el campo de estudio de la historia marítima bajomedieval desde el observatorio de la Corona de Aragón. 